\title{
Volatile compound diversity and conserved alarm behaviour in Triatoma dimidiata
}

\author{
Irving May-Concha ${ }^{1,4}$, Julio C Rojas², Leopoldo Cruz-López ${ }^{2}$, Carlos N Ibarra-Cerdeña ${ }^{3}$ and Janine M Ramsey ${ }^{1 *}$
}

\begin{abstract}
Background: Triatoma dimidiata (Latreille) is a key vector complex of Trypanosoma cruzi, etiologic agent of Chagas disease, as it spans North, Central, and South America. Although morphological and genetic studies clearly indicate existence of at least five clades within the species, there has been no robust or systematic revision, or appropriate nomenclature change for species within the complex. Three of the clades (haplogroups) are distributed in Mexico, and recent evidence attests to dispersal of clades across previously "presumed" monotypic geographic regions. Evidence of niche conservatism among sister species of this complex suggests that geographic dispersal is possible for non-sympatric populations, although no information is available on the behavioural aspects of potential interclade interactions, for instance whether differentiation of chemical signaling or response to these signals could impede communication among the haplogroups.
\end{abstract}

Methods: Volatiles emitted by disturbed bugs, Brindley's (BGs), and metasternal (MGs) glands were identified using solid-phase micro-extraction (SPME) and gas chromatography coupled mass spectrometry (GC-MS). Volatile compounds emitted by BGs and MGs, and those secreted by disturbed nymphs and adults, of the three Mexican T. dimidiata haplogroups were tested for avoidance behaviour by conspecific nymphs and adults using an olfactometer.

Results: Triatoma dimidiata haplogroups all have three age-related alarm responses: absence of response by early stage nymphs, stage-specific response by $4-5^{\text {th }}$ stage nymphs, and a shared $4-5^{\text {th }}$ nymph and adult response to adult compounds. Disturbed bugs released 15 to 24 compounds depending on the haplogroup, among which were three pyrazines, the first report of these organoleptics in Triatominae. Isobutyric acid from BGs was the most abundant molecule in the response in all haplogroups, in addition to 15 (h1) to 21 (h2 and h3) MG compounds. Avoidance behaviour of disturbed bugs and volatiles emitted by BGs were haplogroup specific, while those from the MG were not.

Conclusions: Discriminant and cluster analysis of BG + MG compounds indicate significant separation among the three haplogroups, while alarm response compounds were similar between $\mathrm{h} 2$ and $\mathrm{h} 3$, both distinct from $\mathrm{h} 1$. This latter haplogroup is ancestral phylogenetically to the other two. Our results suggest that alarm responses are a conserved behaviour in the Triatoma dimidiata complex.

Keywords: Triatoma dimidiata complex, Chagas disease, Alarm behaviour, Exocrine compounds, Brindley's glands

\section{Background}

The hematophagous reduviid bug Triatoma dimidiata (Latreille) is an important species complex of Chagas disease vectors in Latin América. This species complex occurs in Mexico, Guatemala, Belize, El Salvador, Honduras, Nicaragua, Costa Rica, Panamá, Colombia, Venezuela, French Guyana, Ecuador, and Peru [1,2]. Its geographic distribution covers the Neotropical region

\footnotetext{
* Correspondence: jramsey@insp.mx

${ }^{1}$ Centro Regional de Investigación en Salud Pública (CRISP), Instituto Nacional de Salud Pública (INSP), Tapachula, Chiapas, México

Full list of author information is available at the end of the article
}

of the North American, Caribbean, and northern region of the South American tectonic plates, and all populations are found across gradients of modified habitats from tropical evergreen and seasonal dry forest, to domestic rural dwellings and cities, having a high tolerance for secondary vegetation and human presence $[3,4]$.

Molecular analysis of the ITS2, cyt b and LSU genes, and classical morphometry, sexual dimorphism, and wing asymmetry analyses have demonstrated the existence of at least three distinct Mexican clades (of the five existing) of $T$. dimidiata [5,6]. Species or sub-species 
assignment for all clades continues to be controversial and without an agreed nomenclature, awaiting more robust analysis of multiple nuclear and mitochondrial genes, as well as other proteomic and phenotypic characters [2,7]. Mexican T. dimidiata haplogroups (h) exhibit highly complex and distinct methyl-branched hydrocarbon configuration from wings, and the variation of epicuticular hydrocarbons demonstrate intraspecific variability into three clades: one originally described and named from the Yucatan peninsula (named herein as haplogroup1, h1), and another composed of two clusters, the second branch h3 (originally described from the Pacific coast of Chiapas), and finally h2 (originally collected from the Gulf of Mexico coast of Veracruz and northern Oaxaca), which includes all populations north of the Isthmus of Tehuantepec [8]. DNA content and cytogenetic studies also differentiate sibling species within the dimidiata complex, suggesting that haplogroups 2 (h2) and 3 (h3) were identical, renaming as sibling species 1, while the original h1 (Yucatan Peninsula) was renamed as species 2 [9]. Despite more than five nomenclature systems for the clades, there is coincidence with more than one gene marker that three Mexican clades exist predominately associated with the Yucatán peninsula (h1), the Gulf of Mexico coastal region, Transvolcanic belt and all regions north of the Isthmus of Tehuantepec (h2), and the Chiapas Pacific coast (h3) [5,10]. Most recently, broader collection and haplogroup typing of specimens has demonstrated dispersal of the $\mathrm{h} 2$ to the Yucatan Peninsula [11], h1 to the northern region of the Isthmus of Tehuantepec previously recognised with predominately $\mathrm{h} 2$, and the presence of $\mathrm{h} 3$ also in the northern region of Chiapas, previously also recognized as predominately with h2 (Ramsey personal communication). If these haplogroups are reproductively isolated [11], and dispersal is increasing along with population migration and commerce, vector control strategies will need to consider the population dynamics and characteristics of all haplogroups, as well as understand their differences or similarities.

Although the general biology and ecology of the dimidiata complex species has been studied [3,10,12,13], knowledge of distinct haplogroups and their chemical ecology is only currently emerging [14,15]. Adult triatomine bugs, including the dimidiata complex species, have two principal exocrine glands, the metasternal (MGs) and Brindley's glands (BGs), which produce important behavioural chemical signals $[16,17]$. Evidence suggests that volatiles mediating sexual behaviour of triatomine bugs are produced in the MGs [18], even though MGs from both females and males produce the same compounds, and males are attracted to female and male MG extracts and to volatiles of mating pairs of $T$. dimidiata [15]. In the headspace of mating pairs and
MGs of one of the T. dimidiata haplogroups, a total of 14 and 15 compounds, respectively, have been isolated [15]. Compounds from MGs are also secreted by disturbed bugs [17], despite the fact that evidence from several studies suggest that alarm pheromones are also produced by the BGs in other triatomine species $[16,17,19]$.

Given significant ecological niche conservation between at least two of the sister haplogroups [20], and increasing dispersal of these populations to alternative ecotopes and geographic regions, the question arises whether differences exist among the haplogroups related to chemical signaling for aggregation, alarm, or reproductive activity. From the public health perspective, the most obvious implications of similarity, or difference, would be selection of control strategies, for the entire Neotropical region of Mexico and Central America. Given haplogroup differentiation using both nuclear and mitochondrial gene markers, we hypothesize that distinct haplogroups will have differentiated chemical profiles either based on secreted molecules, or in their avoidance response to alarm signals. The present study identifies volatile compounds produced by BGs and MGs and emitted by disturbed nymphs and adults of the three aforementioned Mexican haplogroups of $T$. dimidiata. The behavioural responses of nymphs and adults exposed to these volatiles were assessed across haplogroups and life stages.

\section{Methods}

Ethics statement: The Ethics Commission (equivalent to IRB) of the INSP approved all human communication, collaboration and sampling protocols under annual renewal of the permits \#727 and \#1063. All insects collected with the assistance of community members or by searching in or around houses were approved via verbal consent (following collective workshops and individual interview). The Biosafety Commission of the National Institute of Public Health (Comision de Bioseguridad) reviewed and approved the animal care and use protocol with permit numbers CB08-209, and renewed as CB12020. Mexican national guidelines (NORMA Oficial Mexicana NOM-062-ZOO-1999, http://www.fmvz.unam. $\mathrm{mx} / \mathrm{fmvz} /$ principal/archivos/062ZOO.PDF) were adhered to for all animal (NZW rabbits) care and use. This care involved continuous review by competent professionals, diet supplements for iron and multivitamins, and a programmed use based on insect populations. This study did not collect endangered or protected species.

Triatoma dimidiata individuals used in this study were collected in domestic sites from the Yucatan and Chiapas states in Mexico, where all three haplogroups had been previously isolated. Molecular identification of populations analysed was confirmed using ITS2 and 
ND4 $[7,21]$. The nomenclature used herein corresponds to that first used for Mexican haplogroups [2] (Table 1). Field collected bugs were transferred to the insectary of the Centro Regional de Investigación en Salud Pública, Instituto Nacional de Salud Pública (CRISP/INSP), and their faeces checked for the presence of Trypanosoma cruzi. They were bred and maintained separately for a maximum of four generations at $27 \pm 1^{\circ} \mathrm{C}, 70 \pm 5 \% \mathrm{RH}$, a photoperiod of 12: 12 (L: D) h, using rabbit blood source (New Zealand White). Only insects without parasites were used in the experiments and were fed $8 \mathrm{~d}$ before being tested or their volatiles sampled.

\section{Volatile sampling and chemical analyses}

The volatiles emitted by insects and by BGs and MGs were sampled by using the SPME technique. SPME devices, with a fibre coated with $65-\mu \mathrm{m}$ polydimethylsiloxane-divinylbenzene (PDMS-DVB; Supelco, Belfonte, PA), were used to collect all samples. Preliminary analyses indicated that polydimethylsiloxane (PDMS) collected the same compounds but in lower concentrations than the PDMS-DVB. The fibre was exposed to the insect headspace for $60 \mathrm{~min}$ and all samples were maintained at the same temperature and $\mathrm{RH}$ conditions $\left(25 \pm 2^{\circ} \mathrm{C}\right.$ and $65 \pm 10 \% \mathrm{RH}$ ). In all experiments, a control using the same conditions was performed before each test, using an empty flask. After the sampling period, the fibre was withdrawn and inserted into the injector of a GC-MS. The samples were desorbed for $1 \mathrm{~min}$ in the GC injector for analysis.

GC-MS analyses were performed with a GC Varian model CP-3800 equipped with a polar CP-wax 57CB capillary column ( $25 \mathrm{~m}$ by $0.32 \mathrm{~mm}$ and coat thickness of $0.20 \mu \mathrm{m}$ ) coupled with a Varian Saturn 2200 mass spectrometer (Varian, Palo Alto, CA, U.S.A.). The oven temperature was programmed for $40^{\circ} \mathrm{C}$ ( $1 \mathrm{~min}$ hold), then $10^{\circ} \mathrm{C} \mathrm{min}{ }^{-1}$ to $75^{\circ} \mathrm{C}(0 \mathrm{~min})$, then $15^{\circ} \mathrm{C}$ min- 1 to $200^{\circ} \mathrm{C}$, and held for $15 \mathrm{~min}$. The splitless mode was used for the injector with the inlet temperature set at $250^{\circ} \mathrm{C}$. Helium was used as a carrier gas at $1.0 \mathrm{ml} \mathrm{min}^{-1}$. Ionization was by electron impact at $70 \mathrm{eV}$. Compounds were tentatively identified by matching the mass spectra of GC peaks with those in the MS library (NIST 2002). The identities of the compounds were confirmed by comparing the retention times and mass spectra of synthetic standards. The relative abundance of a particular compound was calculated as the proportion of its area to all GC peak areas combined.

Standard compounds for most of those identified in the headspace of disturbed bugs and exocrine glands were obtained at $98-99.5 \%$ purity from commercial sources (Sigma/Aldrich, Toluca, Mexico). The compounds 3methyl-2-hexanone and 3-methyl-2-pentanone were donated by Dr William F. Wood, Chemistry Department, Humboldt State University, Arcata, CA. The compounds 3,5-dimethyl-2-hexanone and 3,5-dimethyl-2-hexanol were donated by Dr Joselyn G. Millar, Department of Entomology, University of California, Riverside, CA. The compound 3-methyl-2-hexanol was prepared from 3methyl-2-hexanone by reduction with sodium borohydride in methanol [22]. The compound 1-octen-3-one was prepared by sodium hypochlorite oxidation of 1-octen-3-ol [22].

\section{Volatiles released by disturbed adults of the dimidiata complex species}

Volatiles released by disturbed and undisturbed bugs were identified from two groups of three female or male bugs of each haplogroup. Bugs were gently introduced into a $50 \mathrm{ml}$ borosilicate glass Erlenmeyer flask and the mouth of the flask covered with aluminium foil and sealed with masking tape. The bugs were vigorously shaken for $30 \mathrm{~s}$, while control bugs were not. An SPME fibre was exposed immediately to the headspace through a pin-size hole in the top of the aluminium foil. After $60 \mathrm{~min}$, the fibre was withdrawn and inserted into the GC-MS injector. Ten replicates each of shaken or unshaken females and males were tested.

\section{Volatiles contained in BGs and MGs}

Volatile compounds contained in female and male BGs and MGs were identified from all three haplogroups. Bugs were placed in a freezer at $-20^{\circ} \mathrm{C}$ for $5 \mathrm{~min}$ to avoid that the glands emptied during procedures, and ten pairs of MG and BG from both females and males were dissected separately under sterile water using a binocular microscope. Glands were placed by pairs into a $2 \mathrm{ml}$ glass conical vial and the mouth of the vial covered

Table 1 Collection sites for Triatoma dimidiata used in this study

\begin{tabular}{|c|c|c|c|c|c|}
\hline Haplogroups & Community & County & State & Longitude (deg/min/s) & Latitude $(\mathrm{deg} / \mathrm{min} / \mathrm{s})$ \\
\hline \multirow[t]{3}{*}{$\mathrm{H} 1$} & Eknakan & Acanceh & Yucatán & $89^{\circ} 22^{\prime} 15^{\prime \prime}$ & $20^{\circ} 45^{\prime} 31^{\prime \prime}$ \\
\hline & San Pedro Chacabal & Motul de Carrillo Puerto & Yucatán & $89^{\circ} 13^{\prime} 00^{\prime \prime}$ & $21^{\circ} 07^{\prime} 06^{\prime \prime}$ \\
\hline & Kantunil & Izamal & Yucatán & $89^{\circ} 02^{\prime} 04^{\prime \prime}$ & $20^{\circ} 47^{\prime} 45^{\prime \prime}$ \\
\hline \multirow[t]{2}{*}{$\mathrm{H} 2$} & Rio Blanco & Berriozabal & Chiapas & $93^{\circ} 10^{\prime} 10^{\prime \prime}$ & $16^{\circ} 25^{\prime} 26^{\prime \prime}$ \\
\hline & Montecristo & Berriozabal & Chiapas & $93^{\circ} 09^{\prime} 56^{\prime \prime}$ & $16^{\circ} 25^{\prime \prime} 27^{\prime \prime}$ \\
\hline $\mathrm{H} 3$ & Los Mangos Manacal, Lomas de Chiapas & Tapachula & Chiapas & $92^{\circ} 14^{\prime} 38^{\prime \prime}$ & $14^{\circ} 54^{\prime} 59^{\prime \prime}$ \\
\hline
\end{tabular}


with aluminium foil sealed with masking tape. Glands were crushed using a thin wire, which was introduced into the vial through a pin-size hole in the aluminium foil, an SPME fibre was then exposed to the headspace for $60 \mathrm{~min}$ after which the fibre was withdrawn and inserted into the GC-MS injector. Ten replicates of each sex, haplogroup, and gland were assayed.

\section{Behavioural responses of nymphs and adults to volatiles emitted by agitated bugs}

In a first experiment, we evaluated the responses of all nymph stages and adults from the three haplogroups to volatiles released by con-haplotypic agitated bugs (e.g. first instar volatiles from h1 vs immature stages and adults from the same h1). Bug responses were recorded using a glass olfactometer consisting of one sample (15 cm high $\times 4.5 \mathrm{~cm}$ diameter) and one release chamber $(5 \mathrm{~cm}$ high $\times 7.5 \mathrm{~cm}$ diameter) (Figure 1A). Activated charcoal filtered air was humidified by passing it through a water jar before introducing it into the olfactometer and then forced into the sample chamber at $500 \mathrm{ml} / \mathrm{min}$; the airflow was regulated by a flowmeter (Gilmont Instruments, Barnant Co., Barrigton, IL). For each treatment, three bugs were introduced into the sample chamber followed by vigorous shaking for $30 \mathrm{~s}$ before starting the bioassay. An empty sample chamber was used as control. A test insect was gently introduced into the release chamber and observed for change in its behaviour for $3 \mathrm{~min}$. Avoidance is defined in this study when bugs raised their head, antennae, and thorax, rubbed their proboscis with their forelegs and walked away from the odour source (downwind). Some bugs also demonstrated agitated running. No change in behaviour was considered a lack of observable response. Twenty replicates of each stage were tested on several odour lots of all stages, over several days. Each odour lot was prepared from three individuals of each specific stage on the same day that assays were performed. After

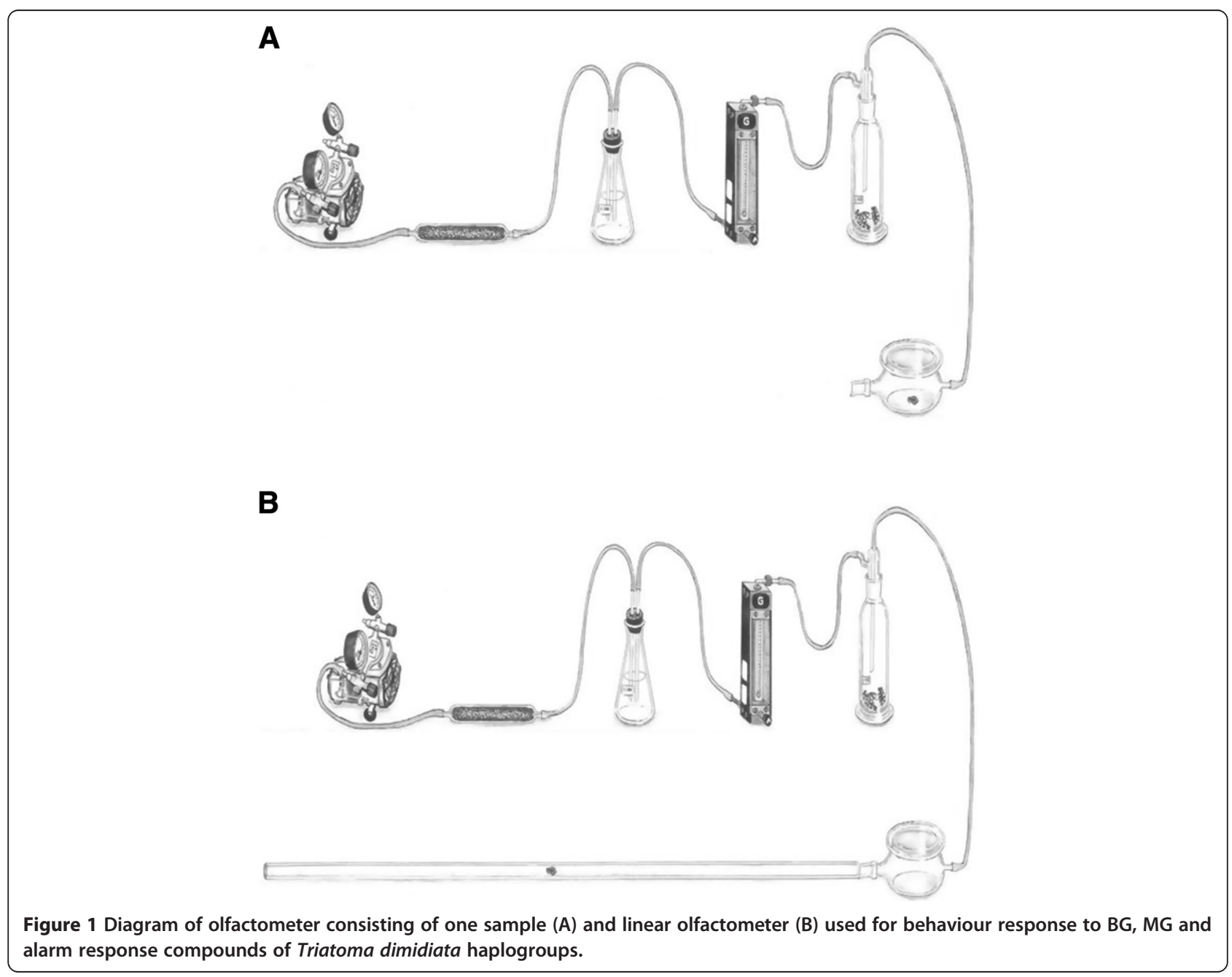


each observation, the olfactometer was washed with detergent and acetone, and dried at $120^{\circ} \mathrm{C}$ for $30 \mathrm{~min}$. All bioassays were performed between 08:00 and 12:00 hrs (no difference was observed between assays conducted at this time vs. 18:00 - 22:00 hrs), although in near total darkness, at $27 \pm 1^{\circ} \mathrm{C}$, and $55 \% \mathrm{RH}$.

In a second group of experiments, the responses to volatiles from agitated $\mathrm{h} 3$ females or males, of $4^{\text {th }}$ and $5^{\text {th }}$ instar nymphs, females, and males from the three haplogroups were evaluated quantitatively using a lineal olfactometer. The olfactometer consisted of a glass tube (100 cm long $\times 2.5 \mathrm{~cm}$ diameter), a release chamber ( $5 \mathrm{~cm}$ high $\times 7.5 \mathrm{~cm}$ diameter), and a sample chamber $(15 \mathrm{~cm}$ high $\times 4.5 \mathrm{~cm}$ diameter) (Figure 1B). Three bugs of each odour source were introduced into the sample chamber which was vigorously shaken for $30 \mathrm{~s}$ before starting a bioassay; an empty sample chamber was used as control. A test insect was gently introduced into the release chamber of the olfactometer and the distance $(\mathrm{cm})$ the bug travelled away from the release chamber was recorded. Twenty (20) replicates were performed using different odour lots, as described previously, over several days. After each observation, the olfactometer was washed and dried as described, and all bioassays were performed with the same environmental conditions mentioned above.

\section{Behavioural responses of nymphs and adults to BG and MG extracts}

The behavioural responses to exocrine gland extracts from h3 males were evaluated in nymphs and adults of the three $T$. dimidiata haplogroups using the linear olfactometer, since preliminary chemical analyses demonstrated that gland extracts of both sexes have the same volatile compounds. Extracts were prepared by placing bugs in a freezer at $-20^{\circ} \mathrm{C}$ for $5 \mathrm{~min}$ to avoid discharge of the gland contents during manipulation, and dissecting the glands underwater using a binocular microscope. Forty (40) glands of each gland type were placed into a $2 \mathrm{ml}$ glass vial containing $1 \mathrm{ml}$ dichloromethane. The conditions and bioassay techniques for this group of experiments were the same as those described above. In all assays, $1 \mu \mathrm{l}$ of the extract was loaded onto a small strip of filter paper for each assay, while $1 \mu \mathrm{l}$ of dichloromethane applied onto filter paper was used for control. The solvent was allowed to evaporate before the filter paper with the extract or control was introduced into the olfactometer sample chamber. The BG and MG extracts were offered as odour bait to $4^{\text {th }}$ and $5^{\text {th }}$ stage nymphs, females, and males of all three $T$. dimidiata haplogroups. Twenty (20) replicates were performed on each stage and haplogroup over several days using the same odour source for all assays.

\section{Statistical analyses}

The data obtained from the linear olfactometer were analyzed by a two-way analysis of variance (ANOVA) with developmental stage/sex and haplogroups. Data from the behavioural responses of $T$. dimidiata to MG extracts were strongly asymmetric, and hence were analyzed with a permutation test for a two-way ANOVA [23]. Data from the volatiles released by disturbed adults or exocrine glands were analyzed using multivariate analysis of variance (MANOVA) to determine if there was a significant difference in the relative abundance of compounds among the haplogroups or stages.

Linear discriminant analysis (LDA) was used to analyze which compounds produced by MG or BG, or released by disturbed bugs, elicit a response differentially among the three haplogroups or according to sex. Analyses were conducted using $R$ project ( $R$ Core Team 2012) and the MASS library [24]. A cluster analysis was used to evaluate the hierarchical similarity among the three haplogroups, using the library VEGAN [25]. A bootstrap re-sampling of dendrograms was conducted to measure topology probability among haplogroups using the library PVCLUST [26]. As in the LDA, the cluster analyses were conducted on the separate matrices of volatiles released by disturbed insects and of those produced by BG, MG, and BG + MG.

\section{Results \\ Volatiles contained in MG and BG glands of dimidiata haplogroups}

The BGs of all T. dimidiata haplogroups emitted only four compounds: propanoic acid, isobutyric acid, pentyl butanoate, and 2-methyl hexanoic acid (Table 2). The major component from BGs for all haplogroups was isobutyric acid, which was also emitted by disturbed bugs. There were significant differences between the relative amounts of the few remaining compounds from the BGs among the three haplogroups $(\mathrm{F}=7.23$; $\mathrm{df}=8, \mathrm{P}<0.001)$, but not between sexes $(\mathrm{F}=0.82 ; \mathrm{df}=4, \mathrm{P}>0.05)$.

The MGs of T. dimidiata h1 and h2 emitted 21 compounds each, while those from $\mathrm{h} 3$ released 15 compounds (Table 3). Nine compounds were present in all haplogroups in more than trace quantities $(\# 1,2,3,5,6,9,14,15$ and 19) and all shared the major compound, 3-methyl-2-hexanone (\#3). Compound \#11 was exclusively present in h3, while compound \#18 was absent in h3, but released in the two other groups in trace quantities. Haplogroups 1 and 2 each had four additional compounds in trace quantities, one of which was identical. MGs contained 18 of the 24 volatile compounds emitted by disturbed bugs. There were significant differences in the relative amounts of MG volatile compounds emitted by disturbed bugs among the three haplogroups $(\mathrm{F}=34.26 ; \mathrm{df}=44 ; P<0.001)$, and between sexes $(\mathrm{F}=7.85 ; \mathrm{df}=22 ; P<0.001)$. 
Table 2 Relative amount $(\%$, mean \pm SE) of volatile compounds in the effluvia of Brindley's glands of female and male Triatoma dimidiata haplogroups

\begin{tabular}{|c|c|c|c|c|c|c|c|}
\hline \multirow[b]{2}{*}{ No } & \multirow[b]{2}{*}{ Compounds/sex } & \multicolumn{2}{|l|}{ Haplogroup 1} & \multicolumn{2}{|l|}{ Haplogroup 2} & \multicolumn{2}{|l|}{ Haplogroup 3} \\
\hline & & q & $\sigma^{\prime \prime}$ & ㅇ & $0^{x}$ & ㅇ & $0^{x}$ \\
\hline 1 & Propanoic acid & $2.37 \pm 0.78(10)^{*}$ & $1.63 \pm 0.65(10)$ & $1.31 \pm 0.27(10)$ & $1.45 \pm 0.48(10)$ & $1.70 \pm 0.33(10)$ & $1.38 \pm 0.49(10)$ \\
\hline 2 & Isobutyric acid & $95.77 \pm 1.38(10)$ & $94.30 \pm 1.92(10)$ & $85.88 \pm 4.19(10)$ & $85.56 \pm 4.16(10)$ & $93.80 \pm 1.85(10)$ & $95.32 \pm 1.88(10)$ \\
\hline 3 & Pentyl butanoate & $0.26 \pm 0.10(10)$ & $0.29 \pm 0.13(10)$ & $0.63 \pm 0.13(10)$ & $1.07 \pm 0.36(10)$ & $0.48 \pm 0.18(10)$ & $0.40 \pm 0.15(10)$ \\
\hline 4 & 2-Methyl hexanoic acid & $1.61 \pm 0.52(10)$ & $3.78 \pm 1.37(10)$ & $12.18 \pm 3.38(10)$ & $11.93 \pm 3.48(10)$ & $3.37 \pm 1.12(10)$ & $2.47 \pm 1.15(10)$ \\
\hline
\end{tabular}

*Numbers between parentheses indicate the detection frequency for each compound ( $\mathrm{N}=10$ samples).

\section{Behavioural responses of nymphs and adults to BG and MG extracts}

The distance bugs travelled away from BG volatiles was affected by haplogroup $(\mathrm{F}=36.85 ; \mathrm{df}=2 ; P<0.001)$, developmental stage/sex $(\mathrm{F}=70.71 ; \mathrm{df}=3 ; P<0.001)$, and the interaction haplogroup*developmental stage/sex ( $\mathrm{F}=18.44 ; \mathrm{df}=6 ; P<0.001$ ) (Figure 2 ). Both sexes of h1 and h2 travelled significantly farther from BG h3 volatiles than their respective nymphs, even though there was no difference in responses of h3 adults and conspecific nymphs. Fourth and $5^{\text {th }}$ instar h 3 nymphs travelled significantly farther from h3 BG volatiles than nymphs from $\mathrm{h} 1$ or h2, while $\mathrm{h} 2$ and $\mathrm{h} 3$ females travelled significantly farther than $\mathrm{h} 1$ females from the h3 BG volatiles. H2 males travelled significantly farther than h1 or h3 males from h3 BG volatiles.

Table 3 Relative amount $(\%$, mean \pm SE) of volatile compounds in the effluvia of metasternal glands of female and male Triatoma dimidiata haplogroups

\begin{tabular}{|c|c|c|c|c|c|c|c|}
\hline \multirow[b]{2}{*}{$\begin{array}{l}\text { Retention } \\
\text { sequence }\end{array}$} & \multirow[b]{2}{*}{ MG compounds } & \multicolumn{2}{|l|}{ Haplogroup 1} & \multicolumn{2}{|l|}{ Haplogroup 2} & \multicolumn{2}{|l|}{ Haplogroup 3} \\
\hline & & 우 & $\sigma^{x}$ & q & $\sigma^{x}$ & q & $\sigma^{x}$ \\
\hline 1 & 3-Methyl-2-pentanone & $6.17 \pm 0.34(10)^{*}$ & $6.47 \pm 0.53(10)$ & $19.25 \pm 0.52(10)$ & $10.01 \pm 0.80(10)$ & $1.67 \pm 0.53(9)$ & $1.26 \pm 0.19(10)$ \\
\hline 2 & 2-Methyl-3-buten-2-ol & $11.88 \pm 0.55(10)$ & $9.19 \pm 0.69(10)$ & $5.11 \pm 0.25(10)$ & $3.09 \pm 0.20(10)$ & $5.21 \pm 2.12(10)$ & $6.77 \pm 3.35(10)$ \\
\hline 3 & 3-Methyl-2-hexanone & $57.52 \pm 2.13(10)$ & $60.73 \pm 2.46(10)$ & $54.66 \pm 1.26(10)$ & $68.83 \pm 1.82(10)$ & $59.95 \pm 10.14(10)$ & $64.42 \pm 8.91(10)$ \\
\hline 4 & 3-Methyl-2-hexanone isomer ${ }^{\dagger}$ & $5.15 \pm 0.26(8)$ & $4.55 \pm 0.30(9)$ & $3.21 \pm 0.22(8)$ & $2.28 \pm 0.26(10)$ & N.D. & N.D. \\
\hline 5 & 3,5-Dimethyl-2-hexanone & $5.29 \pm 0.25(10)$ & $5.43 \pm 0.42(10)$ & $3.37 \pm 0.11(10)$ & $4.05 \pm 0.31(10)$ & $0.94 \pm 0.33(10)$ & $1.61 \pm 0.33(10)$ \\
\hline 6 & $\begin{array}{l}\text { 3,5-Dimethyl-2-hexanone } \\
\text { isomer }^{+}\end{array}$ & $0.42 \pm 0.03(9)$ & $0.43 \pm 0.03(8)$ & $0.07 \pm 0.01(9)$ & $0.04 \pm 0.01(9)$ & $0.16 \pm 0.14(3)$ & $0.09 \pm 0.02(6)$ \\
\hline 7 & 3-Methyl-2-pentanol & $0.11 \pm 0.01(8)$ & $0.13 \pm 0.01(7)$ & $t$ & $t$ & N.D. & N.D. \\
\hline 8 & Octanal & $4.82 \pm 0.30(10)$ & $4.48 \pm 0.24(10)$ & $\mathrm{t}$ & $\mathrm{t}$ & $3.37 \pm 1.12(10)$ & $2.47 \pm 1.15(10)$ \\
\hline 9 & 1-Octen-3-one & $0.99 \pm 0.05(10)$ & $0.94 \pm 0.07(10)$ & $7.38 \pm 0.32(10)$ & $6.99 \pm 0.55(10)$ & $1.77 \pm 1.10(5)$ & $14.26 \pm 7.41(10)$ \\
\hline 10 & 3-Methyl-2-hexanol & $t$ & $t$ & $0.16 \pm 0.01(10)$ & $0.11 \pm 0.01(10)$ & $1.93 \pm 0.93(10)$ & $0.62 \pm 0.21(10)$ \\
\hline 11 & 3-Methyl-2-hexanol isomer ${ }^{\dagger}$ & N.D. & N.D. & N.D. & N.D. & $0.48 \pm 0.18(9)$ & $0.40 \pm 0.15(8)$ \\
\hline 12 & 4-Methyl-2-pentanol & $\mathrm{t}$ & $\mathrm{t}$ & $0.30 \pm 0.02(8)$ & $0.17 \pm 0.01(9)$ & N.D. & N.D. \\
\hline 13 & 6-Methyl-5-hepten-2-one & $t$ & $t$ & $0.16 \pm 0.01(7)$ & $0.13 \pm 0.01(9)$ & $t$ & $0.47 \pm 0.18(10)$ \\
\hline 14 & 3,5-Dimethyl-2-hexanol & $4.00 \pm 0.32(10)$ & $3.57 \pm 0.19(10)$ & $0.16 \pm 0.01(8)$ & $0.11 \pm 0.01(10)$ & $0.67 \pm 0.40(8)$ & $0.85 \pm 0.22(9)$ \\
\hline 15 & 3,5-Dimethyl-2-hexanol isomer ${ }^{\dagger}$ & $0.39 \pm 0.02(10)$ & $0.37 \pm 0.02(8)$ & $0.28 \pm 0.02(7)$ & $0.19 \pm 0.02(10)$ & $0.54 \pm 0.20(6)$ & $0.46 \pm 0.32(5)$ \\
\hline 16 & Dodecanal & $0.58 \pm 0.04(7)$ & $0.60 \pm 0.04(9)$ & $0.50 \pm 0.05(9)$ & $0.43 \pm 0.03(8)$ & N.D. & N.D. \\
\hline 17 & 2-Nonanol & $0.33 \pm 0.02(8)$ & $0.35 \pm 0.02(9)$ & $1.70 \pm 0.11(8)$ & $1.19 \pm 0.09(9)$ & N.D. & N.D. \\
\hline 18 & 3,5-Dimethyl-1-hexene & $t$ & $t$ & $t$ & $t$ & N.D. & N.D. \\
\hline 19 & 1-Octen-3-ol & $0.35 \pm 0.03(10)$ & $0.32 \pm 0.02(9)$ & $1.76 \pm 0.06(10)$ & $1.00 \pm 0.07(9)$ & $0.99 \pm 0.43(6)$ & $2.21 \pm 0.99(9)$ \\
\hline 20 & Decanal & $0.38 \pm 0.03(8)$ & $0.44 \pm 0.03(10)$ & $0.61 \pm 0.02(10)$ & $0.34 \pm 0.02(10)$ & $\mathrm{t}$ & $\mathrm{t}$ \\
\hline 21 & Nonanal & $0.61 \pm 0.04(7)$ & $0.69 \pm 0.04(9)$ & $0.98 \pm 0.04(8)$ & $0.77 \pm 0.04(9)$ & $t$ & $0.84 \pm 0.31(10)$ \\
\hline 22 & 4-Methyl-1-pentanol & $0.83 \pm 0.06(9)$ & $1.14 \pm 0.06(9)$ & $0.17 \pm 0.01(8)$ & $0.14 \pm 0.01(8)$ & N.D. & N.D. \\
\hline
\end{tabular}

*Numbers between parentheses indicate the detection frequency for each compound ( $\mathrm{N}=10$ samples).

${ }^{\dagger}$ Compounds not identified by comparison of pure standards.

$\mathrm{t}$, Traces, traces $<0.1 \%$ abundance; N.D., no detected. 
The developmental stage/sex $(P<0.001)$, and the interaction haplogroup ${ }^{*}$ developmental stage/sex $(P<0.001)$, but not the haplogroup $(P>0.05)$, influenced the distance that the bugs travelled away from MG volatiles (Figure 3). Adult h1 and h2 bugs travelled significantly farther than immature stages and h3 adults from MG volatiles, even though immature h3 stages travelled farther than h1 or h2 nymphs from MG volatiles.

\section{Volatiles released by disturbed adults of the dimidiata complex species}

None of the undisturbed $T$. dimidiata haplogroups released volatile compounds, and in contrast, disturbed bugs released between 13 and 24 compounds, depending on the haplogroup (Table 4). Triatoma dimidiata h3 released significantly fewer compounds as compared to h1 and h2 bugs. Compounds \# 1, 3, 4, 5, 8, 9, 12, 16, 20, and 24 were consistently released by all three disturbed haplogroups. Isobutyric acid (\#24) and 3-methyl-2-hexanone (\#3) accounted for approximately $80 \%$ of the volatiles released by disturbed bugs. Three isomers of pyrazines were emitted by disturbed males and females, although one of these (\#22) was produced in only trace quantities in h1 (Table 4). Overall, there were significant differences in the relative amounts of volatile compounds emitted by disturbed bugs among the three haplogroups $(\mathrm{F}=33.68 ; \mathrm{df}=48 ; P<0.001)$ and between sexes $(\mathrm{F}=4.11 ; \mathrm{df}=24 ; P<0.001)$.

\section{Behavioural responses of nymphs and adults to volatiles emitted by disturbed bugs}

First to third instar nymphs were not affected by volatiles released by disturbed conspecific haplogroup $4^{\text {th }}$ and $5^{\text {th }}$ instar nymphs or adults of any haplogroup (Table 5). Disturbed $4^{\text {th }}$ and $5^{\text {th }}$ instar nymphs released volatiles that affect the behaviour only of conspecific lateinstar nymphs while volatiles emitted by females and males from all haplogroups affected the behaviour only of conspecific $4^{\text {th }}$ and $5^{\text {th }}$ instar nymphs, and both sexes. The distance bugs travelled away from female $T$. dimidiata $\mathrm{h} 3$ was affected by haplogroup type $(\mathrm{F}=35.62 ; \mathrm{df}=2 ; P<$ $0.001)$, developmental stage/sex $(\mathrm{F}=3.16 ; \mathrm{df}=3 ; P=0.02)$, and the interaction of haplogroup*developmental stage/ sex $(\mathrm{F}=4.59 ; \mathrm{df}=6 ; P<0.001)$ (Figure 4$)$. H3 males, females, $4^{\text {th }}$, and $5^{\text {th }}$ instar nymphs had the greatest avoidance for all stages and haplogroups to h3 female volatiles, significant specifically for females and $4^{\text {th }}$ nymphs. Specifically among females, h3 had the highest avoidance, h2 significantly less, and h1 significantly less than either of the other two. Males of h3 and h2 avoided similarly the female volatiles, although both were significantly greater than for h1 males. Fourth stage nymph moved farther from the conspecific female odour source, than the same stages from either h1 or h2, although there was no significant difference in distance travelled by $5^{\text {th }}$ instar nymphs among the three haplogroups.

Similar to that for volatiles from females, the haplogroup $(\mathrm{F}=76.88 ; \mathrm{df}=2 ; P<0.001)$, developmental stage/sex $(\mathrm{F}=$ $7.82 ; \mathrm{df}=3 ; P<0.001)$, and the interaction haplogroup* developmental stage/sex $(\mathrm{F}=15.75 ; \mathrm{df}=6 ; P<0.001)$ influenced the distance that bugs travelled away from $h 3$ males (Figure 5). Similar to the significantly different avoidance by females from all haplogroups to female h3 volatiles, the avoidance of males from all haplogroups was significantly different from each other. Greatest avoidance was from h3

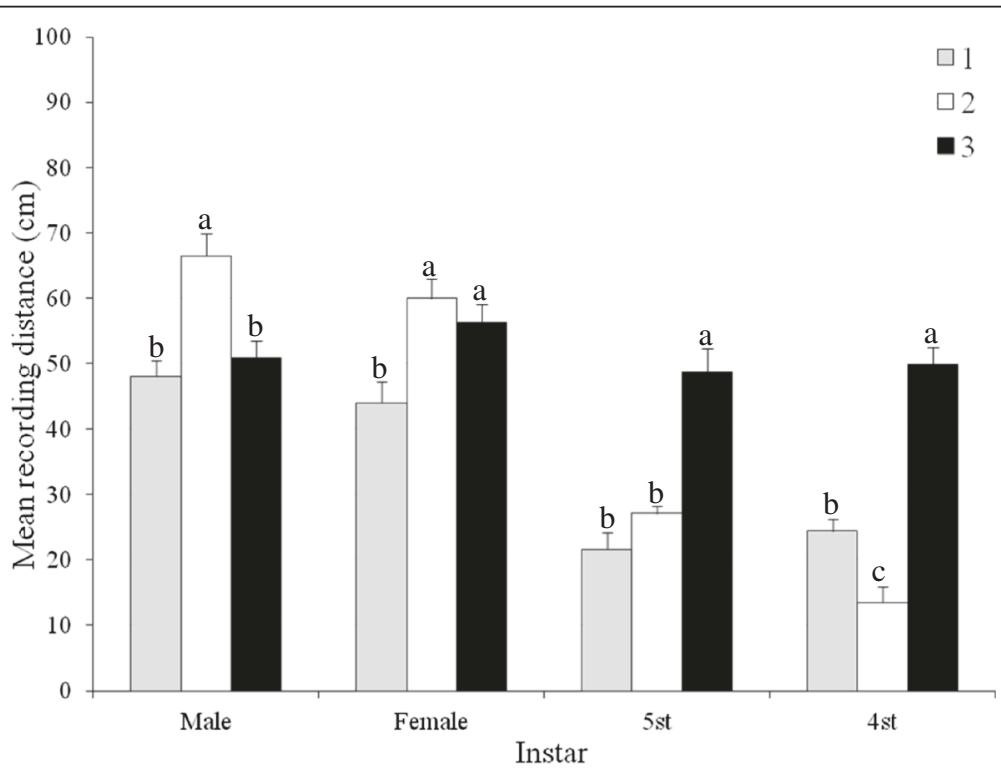

Figure 2 Effect of haplogroup and developmental stage/sex on the response of Triatoma dimidiata to Brindley's gland extracts from males from haplogroup 3. Significant differences are indicated by different letters (Tukey test, $P<0.05$ ). 
males, followed by $\mathrm{h} 2$ and then $\mathrm{h} 1$ males. $\mathrm{H} 3$ females and males travelled farther from $\mathrm{h} 3$ male volatiles than individuals of both sexes from $h 1$ and $h 2$. There was no significant difference in the responses of h1 and h2 nymphs to the male h3 odour source. However, $4^{\text {th }}$ instar h3 nymphs travelled farther than conspecific $5^{\text {th }}$ instar nymphs, females, and males, and h2 $5^{\text {th }}$ instar nymphs travelled significantly farther from male volatiles than $5^{\text {th }}$ instar h1.

\section{Inter-haplogroup differences in BG, MG and volatiles released by disturbed bugs}

The aggregation patterns along the two axes of the LDA were different for BG, MG and disturbed bugs among the three haplogroups (Figure 6A-C). There was no inter-haplogroup differentiation of BG volatiles released (Table 6, Figure 6C), while MG compounds from the three haplogroups clustered significantly separate along both discriminant function axes, and separately for females and males of h1 (Table 7, Figure 6B). MG volatiles were closely associated with the haplogroup/sex group membership, although those released by disturbed insects of haplogroups 2 and 3 were not significantly different (clustered into one group), and both were significantly different from h1 males and females (Table 8, Figure 6A). The 3-methyl-2-pentanol was the most important compound affecting differentiation patterns for the MG LDA (Table 7), while 2-ethylhexenal was an important component in the differentiation of the disturbed bug LDA, albeit in only trace quantities (Table 8). The compounds 3-methyl-2-pentanol, 2-nonanol, and 3-5-dimethyl-1-hexene were also significantly different among haplogroups (Table 8).
Based on compounds emitted by disturbed bugs (98\% confidence in approximate unbiased probability, AU) and compounds contained in the combined BG and MG (96\%), h1 and h2 are more related between them, than either with h3 (Figure 6).

\section{Discussion}

This study has identified three distinct age-related avoidance responses in the Mexican dimidiata complex species, not previously reported in any Triatominae, although these have been reported for other Hemiptera [27,28]. None of the early-instar nymphs (1-3) reacted to conspecific volatiles emitted by late-instar nymphs, or adults, of any dimidiata haplogroups. The lack of response of earlyinstar nymphs to any alarm volatiles could be due to absence or reduced number of receptors, since less olfactory chemosensilla affect odour cues used in long-distance host-orientation [29]. Alternatively, it could be due to incapacity to mount a response mechanism. However, the lack of avoidance or repellent behaviour to volatiles emitted by older stages would increase risk of predation of the early instars, not a beneficial population trait. A second type of response is stage-specific, occurring only in fourth and fifth instar nymphs, while a third type of response, due to compounds released by adults, affects the behaviour of both adults and late stage nymphs. Agitated nymphs induce a stronger avoidance reaction to conspecifics as compared to adults, which indicates that the colony could distinguish an individual's stage based on quantity and odour composition. Similar differential responses have been described in other Hemiptera [30]. An avoidance behaviour is not restricted to males, but also by

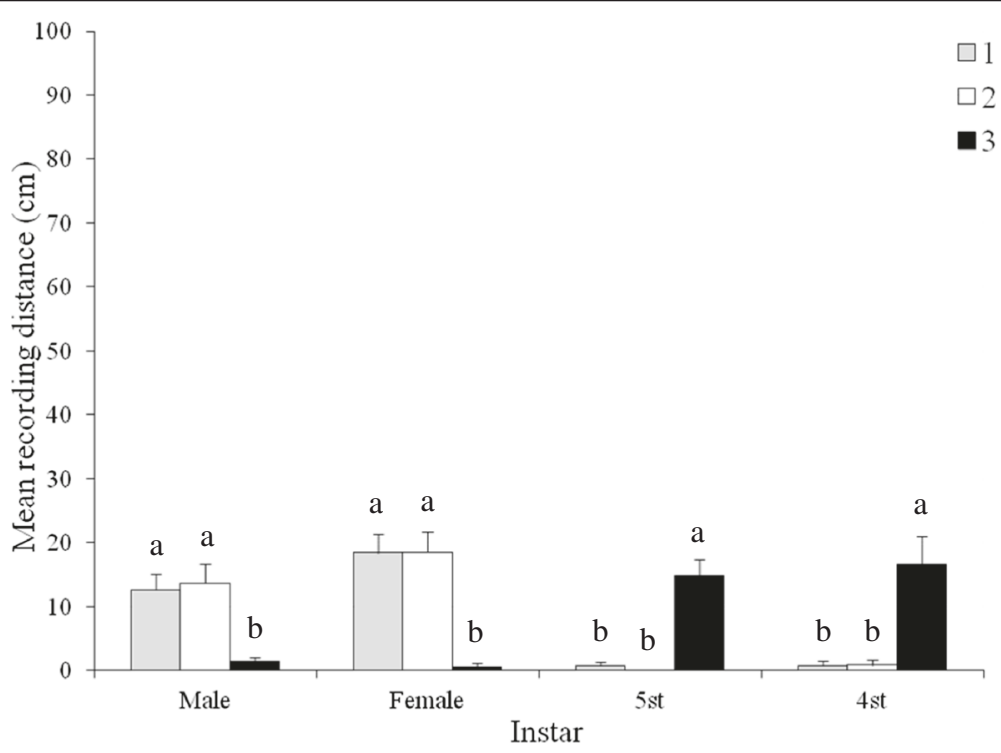

Figure 3 Effect of haplogroup and developmental stage/sex on the response of Triatoma dimidiata to metasternal gland extracts from males from haplogroup 3. Significant differences are indicated by different letters (Tukey test, $P<0.05$ ). 
Table 4 Relative amount $(\%$, mean \pm SE) of volatile compounds collected from the headspace of disturbed female and male Triatoma dimidiata

\begin{tabular}{|c|c|c|c|c|c|c|c|}
\hline \multirow[b]{2}{*}{$\begin{array}{l}\text { Retention } \\
\text { sequence }\end{array}$} & \multirow[b]{2}{*}{ Disturbed compounds } & \multicolumn{2}{|l|}{ Haplogroup 1} & \multicolumn{2}{|l|}{ Haplogroup 2} & \multicolumn{2}{|l|}{ Haplogroup 3} \\
\hline & & $\bar{q}$ & $\sigma^{x}$ & q & $0^{x}$ & o & $0^{x}$ \\
\hline 1 & 3-Methyl-2-pentanone & $0.44 \pm 0.02(9)^{*}$ & $0.50 \pm 0.04(8)$ & $0.36 \pm 0.02(10)$ & $0.35 \pm 0.02(10)$ & $0.15 \pm 0.02(8)$ & $0.50 \pm 0.15(10)$ \\
\hline 2 & 2-Ethylhexenal & $\mathrm{t}$ & $\mathrm{t}$ & $\mathrm{t}$ & $\mathrm{t}$ & N.D & N.D \\
\hline 3 & 3-Methyl-2-hexanone & $36.63 \pm 1.80(10)$ & $42.20 \pm 3.45(10)$ & $44.98 \pm 4.13(10)$ & $41.79 \pm 3.93(10)$ & $9.46 \pm 3.60(10)$ & $34.35 \pm 0.12(10)$ \\
\hline 4 & 3-Methyl-2-hexanone isomer ${ }^{\dagger}$ & $0.25 \pm 0.01(10)$ & $0.31 \pm 0.02(9)$ & $3.49 \pm 0.21(8)$ & $3.23 \pm 0.21(9)$ & $0.39 \pm 0.13(7)$ & $0.33 \pm 0.12(7)$ \\
\hline 5 & 3,5-Dimethyl-2-hexanone & $1.28 \pm 0.05(10)$ & $2.18 \pm 0.09(10)$ & $1.18 \pm 0.09(10)$ & $1.06 \pm 0.08(10)$ & $0.21 \pm 0.11(8)$ & $0.36 \pm 0.15(9)$ \\
\hline 6 & 3,5-Dimethyl-2-hexanone isomer ${ }^{\dagger}$ & $0.24 \pm 0.01(8)$ & $0.31 \pm 0.02(9)$ & $\mathrm{t}$ & $\mathrm{t}$ & $\mathrm{t}$ & $0.14 \pm 0.06(8)$ \\
\hline 7 & 3-Methyl-2-pentanol & $0.43 \pm 0.02(9)$ & t & $\mathrm{t}$ & $\mathrm{t}$ & N.D & N.D \\
\hline 8 & 1-Octen-3-one & $5.20 \pm 0.19(10)$ & $5.91 \pm 0.42(10)$ & $0.50 \pm 0.03(10)$ & $0.48 \pm 0.03(10)$ & $1.39 \pm 0.39(10)$ & $5.95 \pm 1.87(10)$ \\
\hline 9 & 3-Methyl-2-hexanol & $0.84 \pm 0.06(10)$ & $0.96 \pm 0.07(10)$ & $0.77 \pm 0.04(10)$ & $0.60 \pm 0.04(10)$ & $1.23 \pm 0.45(10)$ & $6.72 \pm 4.33(10)$ \\
\hline 10 & 4-Methyl-1-pentanol & $0.10 \pm 0.00(9)$ & $0.14 \pm 0.01(8)$ & $0.25 \pm 0.02(10)$ & $0.23 \pm 0.02(8)$ & N.D & N.D \\
\hline 11 & 6-Methyl-5-hepten-2-one & $\mathrm{t}$ & $\mathrm{t}$ & $\mathrm{t}$ & $\mathrm{t}$ & $\mathrm{t}$ & $0.11 \pm 0.05(7)$ \\
\hline 12 & 3,5-Dimethyl-2-hexanol & $0.45 \pm 0.02(10)$ & $0.55 \pm 0.04(10)$ & $1.08 \pm 0.10(9)$ & $1.03 \pm 0.08(10)$ & $0.43 \pm 0.10(9)$ & $1.13 \pm 0.43(10)$ \\
\hline 13 & 3,5-Dimethyl-2-hexanol isomer ${ }^{\dagger}$ & $0.77 \pm 0.03(8)$ & $0.84 \pm 0.06(9)$ & $1.09 \pm 0.05(8)$ & $0.81 \pm 0.07(9)$ & N.D & N.D \\
\hline 14 & Dodecanal & $0.23 \pm 0.01(8)$ & $0.28 \pm 0.02(9)$ & $0.10 \pm 0.01(7)$ & $0.09 \pm 0.01(9)$ & N.D & N.D \\
\hline 15 & 2-Nonanol & $0.29 \pm 0.01(8)$ & $0.40 \pm 0.02(9)$ & $\mathrm{t}$ & $\mathrm{t}$ & N.D & N.D \\
\hline 16 & 3-Methoxy-2,5-dimethylpirazine & $0.30 \pm 0.01(10)$ & $0.40 \pm 0.02(10)$ & $0.83 \pm 0.09(10)$ & $0.86 \pm 0.05(10)$ & $0.49 \pm 0.23(10)$ & $1.66 \pm 0.63(10)$ \\
\hline 17 & 3-5-Dimethyl-1-hexene & $0.10 \pm 0.01(8)$ & $0.11 \pm 0.01(9)$ & $0.25 \pm 0.02(9)$ & $0.24 \pm 0.02(7)$ & N.D & N.D \\
\hline 18 & 1-Octen-3-ol & $0.58 \pm 0.02(10)$ & $0.84 \pm 0.05(10)$ & $1.22 \pm 0.06(10)$ & $0.92 \pm 0.07(10)$ & N.D & N.D \\
\hline 19 & Decanal & $t$ & $0.21 \pm 0.02(8)$ & $0.26 \pm 0.02(9)$ & $0.24 \pm 0.02(9)$ & N.D & N.D \\
\hline 20 & 2-Methoxy-3-sec-butylpirazine & $0.22 \pm 0.01(9)$ & $0.23 \pm 0.01(10)$ & $0.12 \pm 0.01(10)$ & $0.11 \pm 0.01(10)$ & $0.24 \pm 0.12(8)$ & $0.59 \pm 0.18(10)$ \\
\hline 21 & Nonanal & $1.69 \pm 0.08(7)$ & $2.00 \pm 0.12(9)$ & $0.12 \pm 0.01(9)$ & $\mathrm{t}$ & N.D & N.D \\
\hline 22 & 2-Methoxy-isobutylpirazine & $\mathrm{t}$ & $0.06 \pm 0.00(10)$ & $0.28 \pm 0.01(8)$ & $0.24 \pm 0.02(9)$ & $0.19 \pm 0.07(9)$ & $0.27 \pm 0.13(10)$ \\
\hline 23 & 4-Methyl-1-heptanol & $0.69 \pm 0.03(9)$ & $0.88 \pm 0.05(6)$ & $0.41 \pm 0.02(8)$ & $0.34 \pm 0.03(9)$ & N.D & N.D \\
\hline 24 & Isobutyric acid & $49.11 \pm 2.01(10)$ & $40.48 \pm 4.06(10)$ & $42.39 \pm 4.71(10)$ & $47.03 \pm 4.64(10)$ & $81.5 \pm 516(10)$ & $43.34 \pm 8.22(10)$ \\
\hline
\end{tabular}

*Numbers between parentheses indicate the detection frequency for each compound ( $\mathrm{N}=10$ samples).

${ }^{+}$Compounds not identified by comparison of pure standards.

$\mathrm{t}$,Traces, traces $<0.1 \%$ abundance; N.D., not detected.

females. Benoit et al. used an adult blend in combination with desiccant dusts to target adult bed bugs and a nymph blend to target nymphs in separate pest control trials [31]. Present results suggest that a single mix could be used for both late stage nymphs and adults for $T$. dimidiata.
Although both MG and BG extracts affect the behaviour of dimidiata complex species, those from BG had a more pronounced effect based on concentration and degree of response. When bugs were exposed to volatiles from disturbed females or males, they travelled away

Table 5 Percentage of individuals with avoidance response to conspecific volatiles

\begin{tabular}{|c|c|c|c|c|c|c|c|}
\hline Insect test/Odour source & 1st instar & 2nd instar & 3rd instar & 4th instar & 5th instar & Female & Male \\
\hline 1st instar & $0,0,10^{*}$ & $0,0,0$ & $0,0,0$ & $0,0,0$ & $0,0,0$ & $0,0,0$ & $0,0,0$ \\
\hline 2nd instar & $0,0,10$ & $0,0,15$ & $0,0,0$ & $0,0,15$ & $0,0,0$ & $0,0,0$ & $0,0,0$ \\
\hline 3rd instar & $0,0,0$ & $0,0,0$ & $0,15,25$ & $0,0,0$ & $0,0,0$ & $0,0,0$ & $0,0,0$ \\
\hline 4th instar & $0,0,0$ & $0,0,0$ & $0,10,0$ & $35,60,100$ & $0,20,0$ & $0,5,0$ & $0,0,0$ \\
\hline 5th instar & $0,0,0$ & $0,0,0$ & $0,0,0$ & $0,0,0$ & $80,80,100$ & $0,15,0$ & $0,0,0$ \\
\hline Female & $0,0,0$ & $0,0,0$ & $15,0,15$ & $60,80,100$ & $75,80,100$ & $60,80,100$ & $80,90,100$ \\
\hline Male & $0,0,15$ & $0,0,0$ & $0,0,0$ & $80,80,100$ & $85,100,100$ & $70,85,100$ & $70,75,100$ \\
\hline Air (control) & $0,0,0$ & $0,0,0$ & $0,0,0$ & $0,0,0$ & $0,0,0$ & $0,0,0$ & $0,0,0$ \\
\hline
\end{tabular}

*Indicates the response of haplogroups 1, 2, and 3, respectively. 


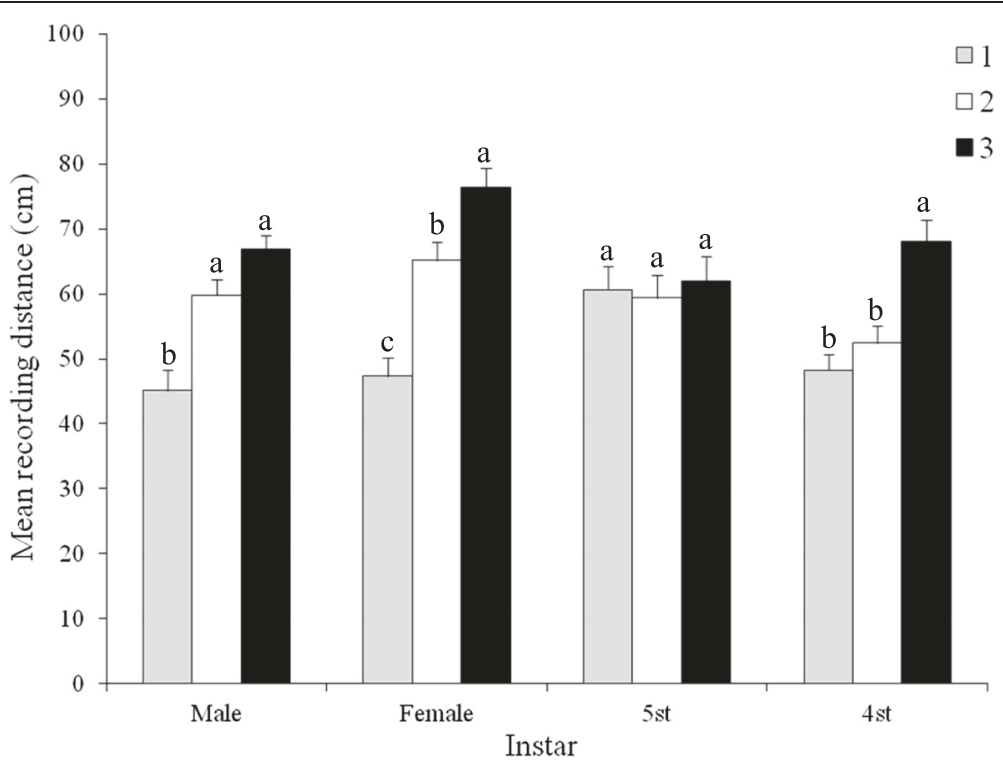

Figure 4 Effect of haplogroup and developmental stage/sex on the response of Triatoma dimidiata to volatiles emitted by females from haplogroup 3. Significant differences are indicated by different letters (Tukey test, $P<0.05$ ).

from odour sources only marginally farther than from BG volatiles alone. Isobutyric acid is the most abundant component of the BG and disturbed blends, in agreement with previous studies indicating that it is associated with alarm and defense functions in triatomines $[19,32,33]$. Manrique identified 14 compounds in the headspace of $T$. infestans BGs, notably more compounds than for any of the dimidiata complex haplogroups [17]. Although butanoic acid has been identified in T. infestans BGs, neither propanoic acid, pentyl butanoate nor 2-methyl hexanoic acid have been reported previously from the BGs of any triatomine. Propionic acid is a repellent for grain storage beetles and weevils and is secreted by Coleoptera and some aphids, while pentyl butanoate is secreted by Cimex and hexanoic acid is secreted by some dipterans as an alarm compound $[19,34]$.

Greater than $83 \%$ of all MG compounds were emitted by disturbed bugs, of all dimidiata haplogroups, although in lowest quantity from h3. Some of these same

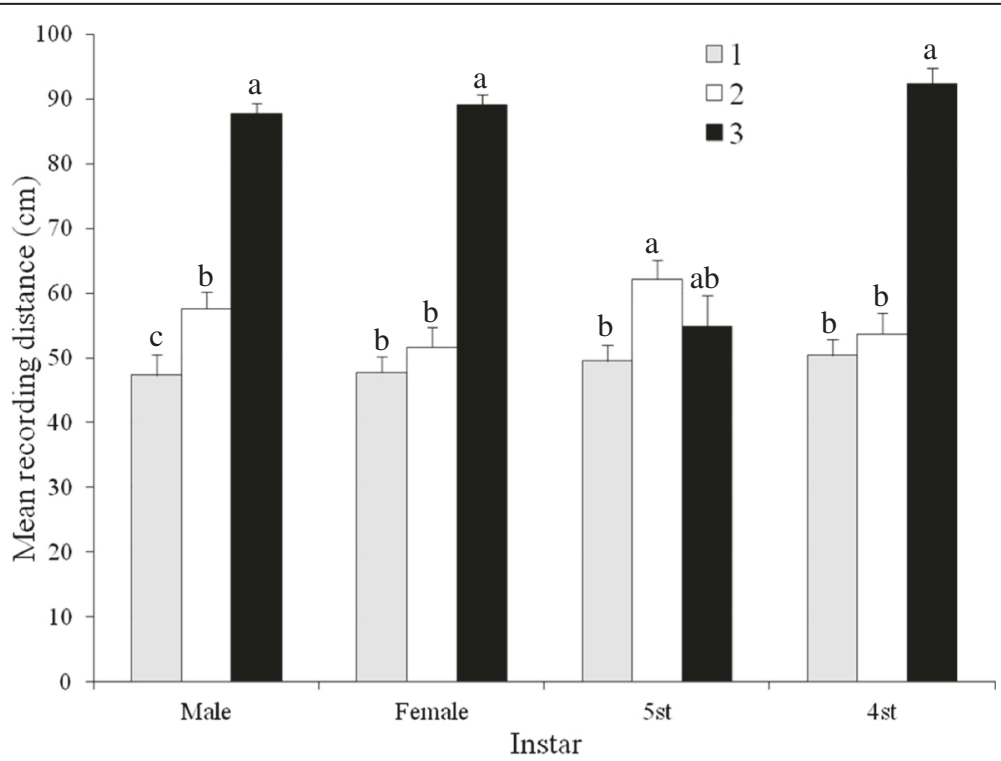

Figure 5 Effect of haplogroup and developmental stage/sex on the response of Triatoma dimidiata to volatiles emitted by males from haplogroup 3. Significant differences are indicated by different letters (Tukey test, $P<0.05$ ). 

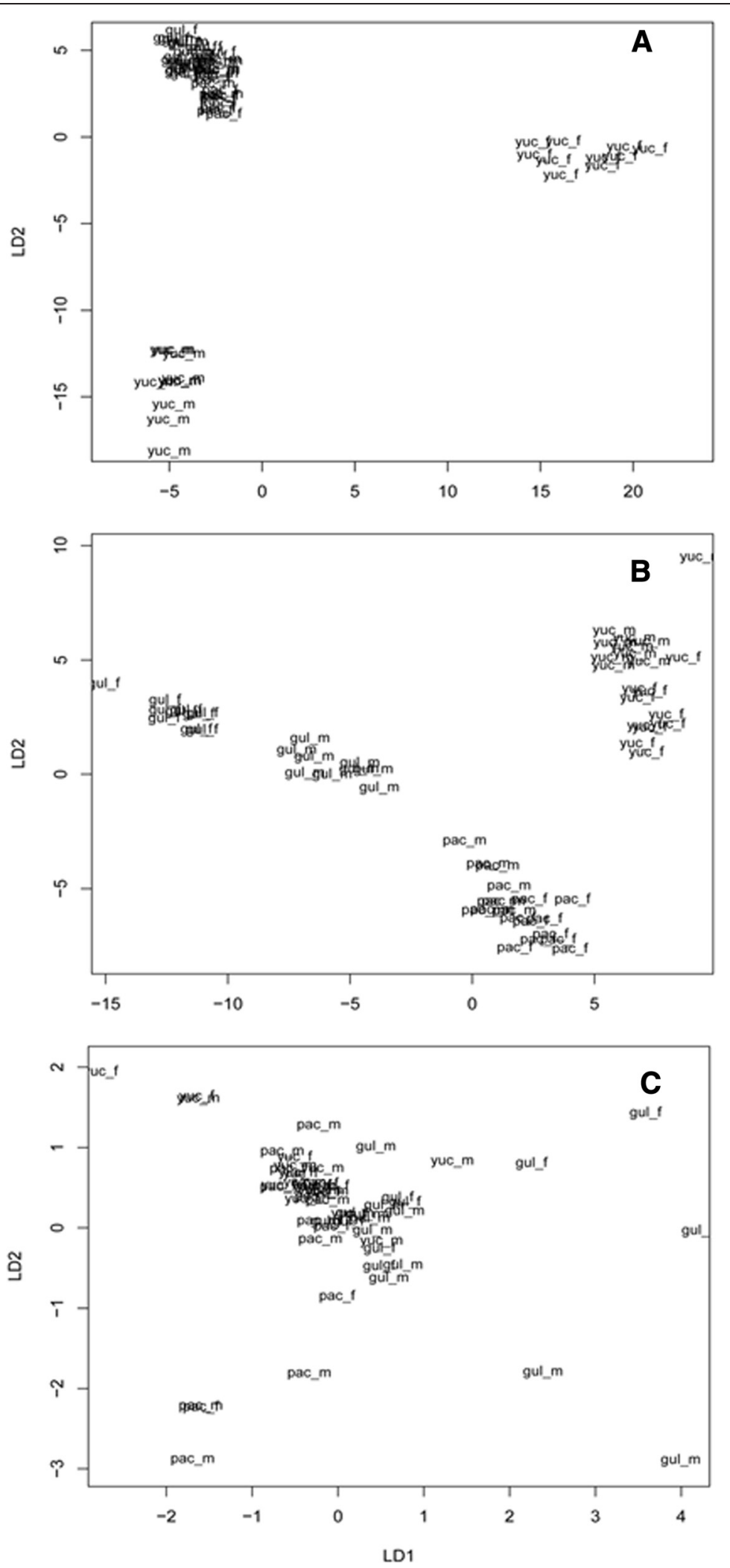

Figure 6 Linear discriminant analysis of volatile responses from disturbed (A) Triatoma dimidiata haplogroups, metasternal (B) or Brindley's (C) glands. (Yuc =h1, Gulf =h2, Pac =h3). 
Table 6 Linear discriminant analysis of BG compounds from Triatoma dimidiata haplogroups

\begin{tabular}{lcc}
\hline Compounds & LD1 (0.62) & LD2 (0.29) \\
\hline Propanoic acid & $-\mathbf{0 . 3 8 8 7}$ & $\mathbf{0 . 3 9 8 3}$ \\
Isobutyric acid & 0.0159 & 0.0251 \\
Pentyl butanoate & $-\mathbf{0 . 2 2 5 4}$ & $\mathbf{- 1 . 5 8 0 8}$ \\
2-Methyl hexanoic acid & 0.1760 & 0.0660 \\
\hline
\end{tabular}

Compounds in bold have the highest LD coefficient.

compounds were found in the headspace of mating pairs of h3 and in a 7-component blend of female MG extracts, one of the major components being 3-methyl2-hexanone, which was attractive to conspecific males [15]. It is interesting to note that this particular compound has also been reported from Dipetalogaster maximus (Uhler) males, a closely-related species to the dimidiata and phyllosoma complexes [35].

Disturbed females and males of h1 and h2 dimidiata complex species released twice as many avoidance compounds, which were more similar to each other than either to those from h3. Compounds produced by h1 and h2 BGs, and particularly MGs, were also more

Table 7 Linear discriminant analysis of MG compounds from Triatoma dimidiata haplogroups

\begin{tabular}{|c|c|c|}
\hline Compounds & LD1 (0.62) & LD2 (0.25) \\
\hline 3-Methyl-2-pentanone & -0.412 & -0.044 \\
\hline 2-Methyl-3-buten-2-ol & 0.245 & -0.115 \\
\hline 3-Methyl-2-hexanone & -0.006 & 0.038 \\
\hline 3-Methyl-2-hexanone isomer & 0.102 & 0.469 \\
\hline 3,5-Dimethyl-2-hexanone & 0.591 & -0.727 \\
\hline 3,5-Dimethyl-2-hexanone isomer & 1.438 & -2.374 \\
\hline 3-Methyl-2-pentanol & 38.049 & 27.704 \\
\hline Octanal & 0.780 & -0.471 \\
\hline 1-Octen-3-one & 0.014 & -0.014 \\
\hline 3-Methyl-2-hexanol & -0.167 & -0.115 \\
\hline 3-Methyl-2-hexanol isomer & -4.094 & 0.685 \\
\hline 4-Methyl-2-pentanol & -8.376 & 1.656 \\
\hline 6-Methyl-5-hepten-2-one & -3.830 & 1.783 \\
\hline 3,5-Dimethyl-2-hexanol & -0.569 & 0.117 \\
\hline 3,5-Dimethyl-2-hexanol isomer & 0.947 & -0.631 \\
\hline Dodecanal & -3.564 & 2.681 \\
\hline 2-Nonanol & -1.484 & 1.742 \\
\hline 3,5-Dimethyl-1-hexene & -1.570 & 16.471 \\
\hline 1-Octen-3-ol & -0.335 & 0.090 \\
\hline Decanal & -2.212 & -1.096 \\
\hline Nonanal & -1.461 & 1.312 \\
\hline 4-Methyl-1-pentanol & -0.638 & 7.452 \\
\hline
\end{tabular}

Compounds in bold have the highest LD coefficient.
Table 8 Linear discriminant analysis of compounds emitted by disturbed bugs from Triatoma dimidiata haplogroups

\begin{tabular}{|c|c|c|}
\hline Compounds & LD1 (0.62) & LD2 (0.25) \\
\hline 3-Methyl-2-pentanone & 0.167 & -7.178 \\
\hline 2-ethylhexenal & -13.355 & -42.952 \\
\hline 3-Methyl-2-hexanone & 0.051 & -0.042 \\
\hline 3-Methyl-2-hexanone isomer & -0.379 & 1.707 \\
\hline 3,5-Dimethyl-2-hexanone & -0.934 & -1.117 \\
\hline 3,5-Dimethyl-2-hexanone isomer & -0.138 & 0.762 \\
\hline 3-Methyl-2-pentanol & 50.690 & 20.444 \\
\hline 1-Octen-3-one & -0.153 & 0.884 \\
\hline 3-Methyl-2-hexanol & -0.037 & 0.088 \\
\hline 4-Methyl-1-pentanol & 3.441 & 11.936 \\
\hline 6-Methyl-5-hepten-2-one & -2.030 & 13.130 \\
\hline 3,5-Dimethyl-2-hexanol & 0.008 & 0.252 \\
\hline 3,5-Dimethyl-2-hexanol isomer & 1.633 & 1.929 \\
\hline Dodecanal & -2.320 & 8.374 \\
\hline 2-Nonanol & -2.452 & -31.235 \\
\hline 3-Methoxy-2,5-dimethylpirazine & 0.165 & -1.190 \\
\hline 3-5-Dimethyl-1-hexene & -18.304 & 2.681 \\
\hline 1-Octen-3-ol & -0.998 & -3.257 \\
\hline Decanal & -5.073 & 6.075 \\
\hline 2-Methoxy-3-sec-butylpirazine & -0.197 & -0.196 \\
\hline Nonanal & -0.050 & -2.097 \\
\hline 2-Methoxy-isobutylpirazine & -0.240 & -0.709 \\
\hline 4-Methyl-1-heptanol & 1.468 & 0.609 \\
\hline Isobutyric acid & 0.002 & 0.001 \\
\hline
\end{tabular}

similar between them than either to h3. While phylogenetic studies of the dimidiata complex using ITS-2, cyt b, and ND4 clearly separate the three haplogroups $[2,6,7]$ other studies using the $16 \mathrm{~S}$, cyt b, morphometry, epicuticular hydrocarbons, and cytogenetics [5,8,9,36] cluster h2 and h3 into one clade, with h1 in a separate ancestral clade to the former $[2,6,8]$. Discriminant and cluster analysis of exocrine gland volatile compounds clearly differentiate the three haplogroups, while alarm response compounds alone indicate a similar response by $\mathrm{h} 2$ and $\mathrm{h} 3$, both distinct from h1. The phylogenetic distinction of haplogroups is apparently not a barrier for conserved alarm responses in this species complex.

Volatile compounds not produced in either BG or MG by disturbed bugs were the compounds 3-methoxy-2, 5dimethylpyrazine, 2-methoxy-3-sec-butylpyrazine, and 2methoxy-isobutylpyrazine, reported here for the first time for Triatominae. Preliminary analyses indicate that these compounds are also secreted by $3^{\text {rd }}$ stage nymphs of all three haplogroups, although the exocrine glands or 
tissues which produce them have yet to be identified (not contained in faeces). Pyrazines are compounds found in a wide range of organisms (from bacteria to mammals) and are some of the most ubiquitous natural odours of plants in nature [37]. They are major organoleptic agents involved in communal defense odours in insects and via multimodal mechanisms of both chemical and visual cues, providing both an alarm and a tracking/ attractant role. Pyrazines are secreted by bacterial symbionts and enhance attraction of natural predators to aphids [38] and Anastrepha ludens [39]. They are used for defensive behavior by Phyllium westwoodii, a phasmid leaf insect [40], and as both attractant or aggregant (at low concentration), and as alert and defense (higher concentration) in ants and ladybugs $[41,42]$. They have been reported from at least four insect orders, including Orthoptera, Hemiptera (Pentatomidae and Cercopidae), Lepidoptera, and Coleoptera and they are commonly associated with warning coloration and mimicry in aposematically coloured insects [43]. Their low olfactory threshold (as low as $0.002 \mathrm{ppb}$ in water for some pyrazines) and great persistence are important characteristics providing their dual functions, according to concentration: at low concentrations an attractive odour, while at higher concentrations a disagreeable stench. The fact that all the dimidiata haplogroups produce pyrazines potentially for communication with conspecifics, suggests that there is an evolutionary advantage to preserving the phenotype. Given the low density of bugs in natural landscapes, it is not surprising that they may use aggregation signally, and similar to other social insects, they may use the same compound for both alarm and defensive strategies. This is even more interesting given that pyrazines may also be used as a host mimicry strategy to deal with an otherwise hostile nest community.

\section{Conclusions}

Discriminant and cluster analysis of volatile compounds from Brindley's and metasternal glands of the three Mexican haplogroups of $T$. dimidiata indicate significant separation among the three haplogroups, while alarm response compounds of disturbed bugs (which include compounds from other exocrine tissues) were similar between $\mathrm{h} 2$ and $\mathrm{h} 3$, both distinct from the ancestral h1. The phylogenetic distinction among the haplogroups based on BG and MG compounds is therefore not a barrier for conserved alarm responses among these haplogroups. All Mexican haplogroups of the dimidiata complex produce and emit pyrazines, compounds not previously reported in the Triatominae. Although the exocrine glands or tissues that produce these compounds have yet to be identified, it is noteworthy that they have been conserved phylogenetically. Their role in conspecific aggregation, alarm, and host mimicry may optimize social interactions and survival of this complex of species.

\section{Competing interests}

The authors declare that they have no competing interests.

\section{Authors' contributions}

Study concept: IJMC, JCRL, JMR, LCCL. Collected data: IJMC, LCCL. Data analysis: IJMC, CNIC, JMR, JCRL. Manuscript: IJMC, JMR, JCR, CNIC, LCCL. All authors read and approved the final version of the manuscript.

\section{Acknowledgments}

We are grateful for the technical assistance of Bernardino Díaz Díaz (ECOSUR) and Antonio López Morales (CRISP), and the statistical advice of Javier Valle-Mora (ECOSUR). We also thank Dr. Jocelyn G. Millar (Department of Entomology, University of California, Riverside) for supplying samples of 3, 5-dimethyl-2hexanone and 3, 5-dimethyl-2-hexanol, and Dr. William F. Wood (Department of Chemistry, Humboldt State University, Arcata, CA) for supplying samples of 3-methyl-2-pentanone and 3-methyl-2-hexanone used in this study. This study was supported by funding from CONACyT FONSEC Salud \#161405 to JMR.

\section{Author details}

${ }^{1}$ Centro Regional de Investigación en Salud Pública (CRISP), Instituto Nacional de Salud Pública (INSP), Tapachula, Chiapas, México. ${ }^{2}$ Grupo de Ecología y Manejo de Artrópodos, El Colegio de la Frontera Sur (ECOSUR), Carretera Antiguo Aeropuerto km 2.5, Tapachula, Chiapas, México. ${ }^{3}$ Departamento de Ecologia Humana, Centro de Investigación y de Estudios Avanzados del Instituto Politécnico Nacional (Cinvestav), Mérida, Yucatán, México. ${ }^{4}$ Departamento de Neuroetología Ecológica, Centro de Investigaciones Científicas y Transferencia de Tecnológica a la Producción (CICyTTP), Diamante, Entre Ríos, Argentina.

Received: 8 October 2014 Accepted: 21 January 2015 Published online: 06 February 2015

\section{References}

1. Schofield CJ. Evolución y control del Triatoma dimidiata. In: Organización Panamericana de la Salud, editor. Taller para el establecimiento de pautas técnicas en el control de Triatoma dimidiata. San Salvador: Organización Panamericana de la Salud; 2002. p. 12-8. (Document OPS/HCP/HCT/214/02).

2. Bargues MD, Klisiowicz DR, González-Candelas F, Ramsey JM, Monroy C, Ponce $C$, et al. Phylogeography and genetic variation of Triatoma dimidiata, the main Chagas disease vector in Central America, and its position within the genus Triatoma. PLoS Negl Trop Dis. 2008. doi:10.1371/journal. pntd.0000233

3. Ibarra-Cerdeña Cl, Sánchez-Cordero V, Peterson AT, Ramsey JM. Ecology of North American Triatominae. Acta Trop. 2009;110:178-86.

4. Grisales N, Triana O, Angulo V, Jaramillo N, Parra-Henao G, Panzera F, et al. Diferenciación genética de las tres poblaciones colombianas de Triatoma dimidiata (Latreille, 1811) mediante análisis molecular del gen mitocondrial ND4. Biomedica. 2010;30:207-14.

5. Lehmann P, Ordoñez R, Ojeda-Baranda R, Mendez de Lira J, Hidalgo-Sosa L, Monroy C, et al. Morphometric analysis of Triatoma dimdiata populations (Reduviidae:Triatominae) from México and Northern Guatemala. Mem Inst Oswaldo Cruz. 2005;100:477-82.

6. Marcilla A, Bargues MD, Ramsey JM, Magallon-Gastelum E, SalazarSchettinom PM, Abad-Franch F, et al. The ITS-2 of the nuclear rDNA asa molecular marker for populations, species, and phylogenetic relationships in Triatominae (Hemiptera: Reduviidae), vectorsof Chagas disease. Mol Phylogenet Evol. 2001;18:136-42.

7. Monteiro FA, Peretolchina T, Lazoski C, Harris K, Dotson EM, Abad-Franch F, et al. Phylogeographic Pattern and Extensive Mitochondrial DNA Divergence Disclose a Species Complex within the Chagas Disease Vector Triatoma dimidiata. PLoS ONE. 2013;8(8):e70974. doi:10.1371/journal.pone.0070974.

8. Calderon-Hernandez GM, Girotti JR, Juarez PM. Cuticular hidrcocarbons of Triatoma dimidiata (Hemiptera:Reduviidae): Intraespecific variation and chemotaxonomy. J Med Entomol. 2011;48:262-71.

9. Panzera F, Ferrandis I, Ramsey JM, Ordoñez R, Salazar-Schettino PM, Cabrera M, et al. Chromosomal variation and genome size support existence of cryptic species of Triatoma dimidiata with different epidemiological importance as Chagas disease vectors. Trop Med Int Health. 2006;11:1092-103. 
10. Zeledon R, Rojas CJ, Urbina A, Cordero M, Gamboa SH, Lorosa ES, et al. Ecological control of Triatoma dimidiata (Latreille, 1811): Five years after a Costa Rican pilot Project. Mem Inst Oswaldo Cruz. 2008;103:619-21.

11. Dorn PL, Calderon C, Melgar S, Moguel B, Solorzano E, Dumonteil E, et al. Two distinct Triatoma dimidiata (Latreille, 1811) taxa are found in sympatry in Guatemala and Mexico. PLoS Negl Trop Dis. 2009;3(3):e393. doi:10.1371/ journal.pntd.0000393. Epub 2009 Mar 10.

12. Abad-Franch F, Ferraz G, Campos C, Palomeque FS, Grijalva MJ, Aguilar HM, et al. Modeling disease vector ocurrence when detection is imperfect: infestation of Amazonian palm trees by Triatominae bugs at three spatial scales. Plos Negl Trop Dis. 2010;4:e620. doi:10.1371/journal.pntd.0000620.

13. Monroy CM, Bustamante DM, Rodas A, Enriquez ME, Rosales R. Habitats, dispersion and invasion of sylvatic Triatoma dimidiata (Hemiptera: Reduviidae: Triatominae) in Peten, Guatemala. J Med Entomol. 2003;40:800-6.

14. Milne MA, Ross EJ, Sonenshine DE, Kirsch P. Attraction of Triatoma dimidiata and Rhodnius prolixus (Hemiptera:Reduviidae) to combinations of host cues tested at two distances. J Med Entomol. 2009:46:1062-73.

15. May-Concha I, Rojas JC, Cruz-López L, Millas JG, Ramsey JM. Volatiles compounds emitted by Triatoma dimidiata, a vector of Chagas disease: Chemical identification and behavioral analysis. Med Vet Entomol. 2013;27:165-74

16. Cruz-López L, Malo EA, Rojas JC, Morgan ED. Chemical ecology of Triatomine bugs: vectors of Chagas disease. Med Vet Entomol. 2001;15:351-7.

17. Manrique G, Vitta ACR, Ferreira RA, Zani CL, Unelius CR, Lazzari CR, et al. Chemical communication in Chagas disease vectors. Source, identity and potential function of volatiles released by the metasternal and Brindley's glands of Triatoma infestans adults. J Chem Ecol. 2006;32:2035-52.

18. Vitta RA, Bohman B, Unelius CR, Lorenzo MG. Behavioral and electrophysiological responses of Triatoma brasiliensis males to volatiles produced in the metasternal glands of females. J Chem Ecol. 2009;35:1212-21.

19. González Audino GP, Alzogaray RA, Vannesa C, Masuh H, Fontán A, Gatti P, et al. Volatile compounds secreted by Brindley's glands of adult Triatoma infestans: identification and biological activity of previously unidentified compounds. J Vector Ecol. 2006:32:75-82.

20. Ibarra-Cerdeña CN, Zaldivar-Riveron A, Peterson AT, Sanchez-Cordero V, Ramsey JM. Phylogeny and niche conservatism in North and Central American triatomine bugs (Hemiptera: Reduviidae: Triatominae), vectors of Chagas' disease. PLOS NTD. 2014; 8(10): doi:10.1371/journal.pntd.0003266.

21. Richards B, de la Rua NM, Monroy C, Stevens L, Dorn PL. Novel polymerase chain reaction-restriction fragment length polymorphism assay to determine internal transcribed spacer-2 group in the Chagas disease vector, Triatoma dimidiata (Latreille, 1811). Mem Inst Oswaldo Cruz. 2013:108:395-8.

22. Pavia DL, Lampman GM, Kriz GS, Engel RG. Introduction to Organic Laboratory Techniques, a Microscale Approach. Philadelphia: Saunders College Publishing; 1990.

23. Wheeler DJ, Chambers DS. Understanding statistical process control. Knoxville: SPC Press; 2010.

24. Venables WN, Ripley BD. Modern Applied Statistics with S. New York: Springer; 2002.

25. Oksanen J, Guillaume FB, Kindt R, Legendre P, Minchin PR, O'Hara RB, et al. Community Ecology Package R version 2.0-6; 2013. http://CRAN.R-project. org/package=vegan

26. Suzuki R, Shimodaira H. Hierarchical Clustering with P-Values via Multiscale Bootstrap Resampling. R package version 1.2-2; 2011. http://CRAN.R-project. org/package=pvclust).

27. Prudic KL, Noge K, Becerra JX. Adults and nymphs do not smell the same: The different defensive compounds of the giant mesquite bug (Thasus neocalifornicus: Coreidae). J Chem Ecol. 2008:34:734-41.

28. Liedtke HC, Åbjörnsson K, Harraca V, Knudsen JT, Wallin EA, Hedenström E, et al. Alarm Pheromones and Chemical Communication in Nymphs of the Tropical Bed Bug Cimex hemipterus (Hemiptera: Cimicidae). PLOS ONE. 2011;6:e18156. doi:10.1371/journal.pone.0018156.

29. Mclver SB. Sensilla of haematophagous insects sensitive to vertebrate host-associated stimuli. Insect Sci Appl. 1987;8:627-35.

30. Harraca V, Ryne C, Ignell R. Nymphs of the common bed bug (Cimex lectularius) produce anti-aphrodisiac defence against conspecific males. BMC Biol. 2010;8:121. doi:10.1186/1741-7007-8-121.

31. Benoit JB, Phillips SA, Croxall TJ, Christensen BS, Yoder JA, Denlinger DL, Addition of alarm pheromone components improves the effectiveness of desicant dusts against Cimex lectularius. J Med Entomol. 2009;46:572-9.
32. Minoli S, Palottini F, Crespo JG, Manrique G. Dislodgement effect of natural semiochemicals released by disturbed triatomines: a possible alternative monitoring tool. J Vector Ecol. 2013;38:353-60.

33. Cruz-López L, Morgan ED, Ondarza RN. Brindley's gland exocrine products of Triatoma infestans. Med Vet Entomol. 1995;9:403-6.

34. Germinara GS, De Cristofaro A, Rotundo G. Behavioral responses of adult Sitophilus granarius to individual cereal volatiles. J Chem Ecol. 2008;34:523-9.

35. Guerenstein PG, Guerin PM. A comparison of volatiles emitted by adults of three triatomine species. Entomol Exp Appl. 2004;111:151-5.

36. Dorn PL, Monroy C, Curtis A. Triatoma dimidiata (Latreille, 1811): A review of its diversity across its geographic range and the relationship among populations. Infect Genet Evol. 2007;7:343-52.

37. Rowe C, Guilford T. The evolution of multimodal warning displays. Evolutionary Ecol. 2000;13:655-71.

38. Leroy PD, Sabri A, Verheggen FJ, Francis F, Thonart P, Haubruge E. The semiochemically mediated interactions between bacteria and insects. Chemoecol. 2011;21:113-22.

39. Robacker DC, Lauzon CR, He X. Volatiles production and attractiveness to the Mexican fruit fly of Enterobacter agglomerans isolated from apple maggot and Mexican fruit flies. J Chem Ecol. 2004;30:1329-47.

40. Dossey AT, GottardoM WJM, Roush WR, Edison A. Alkyldimethylpyrazines in the defensive spray of Phyllium westwoodii: A first for Orden Phasmantodea. J Chem Ecol. 2009;35:861-70.

41. Billen J. Signal variety and communication in social insects. Proc Netherlands Entomol Soc Meet. 2006;17:9-25.

42. Sharma K, Vander-Meer RK, Fadamiro HY. Phorid fly, Pseudacteon tricupsis, response to alkylpyrazine analogs of a fire ant, Solenopsis invicta, alarm pheromone. J Ins Physiol. 2011;57:939-44.

43. Rothschild M, Moore BP. Pyrazines as alerting signals in toxic plants and insects. In: Labeyrie V, Fabres G, Fachaise D, editors. Insect-Plants. Dordrecht: W. Junk; 1987.

\section{Submit your next manuscript to BioMed Central and take full advantage of:}

- Convenient online submission

- Thorough peer review

- No space constraints or color figure charges

- Immediate publication on acceptance

- Inclusion in PubMed, CAS, Scopus and Google Scholar

- Research which is freely available for redistribution

Submit your manuscript at www.biomedcentral.com/submit
C Biomed Central 